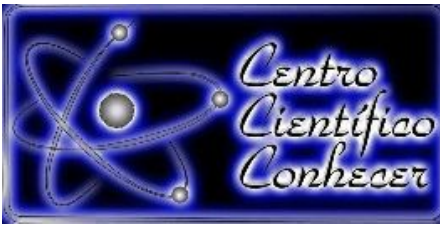

\title{
O SABER ETNOBOTÂNICO SOBRE PLANTAS MEDICINAIS NA COMUNIDADE DA BRENHA, REDENÇÃO, CE
}

Luzivone da Silveira do Nascimento Santos ${ }^{1}$, Maria Gorete Flores Salles ${ }^{2}$, Ciro de Miranda Pinto ${ }^{3}$, Olienaide Ribeiro de Oliveira Pinto ${ }^{4}$, Inti Campos Salles Rodrigues ${ }^{5}$

1Bacharel em Agronomia / Universidade da Integração Internacional da Lusofonia Afro-Brasileira (UNILAB), Redenção-CE, Brasil.

${ }^{2}$ Professora Doutora da UNILAB, Redenção-CE, Brasil. E-mail: gorete@unilab.edu.br

${ }^{3}$ Professor Doutor da UNILAB, Redenção-CE, Brasil.

${ }^{4}$ Professora no Mestrado Acadêmico em Sociobiodiversidade e Tecnologias Sustentáveis da UNILAB, Redenção-CE, Brasil.

${ }^{5}$ Mestre em Ciências Veterinárias/ Universidade Estadual do Ceará (UECE), Fortaleza-CE, Brasil.

Recebido em: em: 14/07/2018 - Aprovado em: 28/07/2018 - Publicado em: 31/07/2018 DOI: 10.18677/Agrarian_Academy_2018a40

\section{RESUMO}

A Etnobotânica se ocupa do estudo sobre o conhecimento e as conceituações desenvolvidas por qualquer sociedade a respeito do mundo vegetal, englobando a maneira como um grupo social classifica as plantas, bem como, as utilizam. O trabalho ocorreu no período de maio a dezembro de 2017 na comunidade rural da Brenha, no município de Redenção, região do Maciço de Baturité, no estado do Ceará. Com o objetivo de realizar um levantamento etnobotânico sobre o conhecimento e uso das plantas medicinais e suas aplicações pelos comunitários da Brenha, que foi realizado por entrevistas duas vezes por semana utilizando um questionário estruturado. Os dados obtidos através das informações coletadas foram apresentados na forma de tabela e gráficos indicando quais as plantas e as partes da planta que são utilizadas, para qual enfermidade é indicada e sua forma de uso, o nome popular, a classificação, o nome cientifico e a família botânica. Foram entrevistadas 35 famílias, e todas as pessoas que se dispuseram a participar tinham conhecimento sobre as plantas medicinais adquiridas dos seus antepassados, mostrando que os saberes passam de geração a geração. Foram citadas 27 variedades de plantas, sendo essas de grande importância para a comunidade, na prevenção e combate das doenças comuns. A planta mais citada foi hortelã (Mentha $s p)$ e o malvarisco (Plectranthus ambroinicus), usadas para as doenças gastrointestinais, e doenças respiratórias, e a parte mais utilizada foi a folha em forma de chá. Portanto, as plantas medicinas são uma alternativa fundamental no combate de algumas enfermidades.

PALAVRAS-CHAVE: conhecimento tradicional, etnoconhecimento, fitoterápicos. 


\title{
THE ETHNOBOTANICAL KNOWLEDGE ABOUT MEDICINAL PLANTS IN THE COMMUNITY OF THE BRENHA, REDENÇÃO-CE
}

\begin{abstract}
Ethnobotany deals with the study of knowledge and conceptualizations developed by any society regarding the plant world, encompassing the way a social group classifies plants, as well as using such plants. The work occurred during the period of may december, 2017 in the rural community of Brenha municipality of Redenção region of the Massif de Baturité, in the state of Ceará. With the objective of carrying out an ethnobotanical survey on the knowledge and use of medicinal plants and their applications by the community of Brenha, a structured questionnaire was conducted twice a week. The data obtained through the information collected will be presented in the form of a table and graphs indicating the most used plants and the parts used for which disease is indicated and their use, the popular name, classification of the scientific name and the botanical family. It was interviews with 35 families, and all the people who were willing to participate had a knowledge about the medicinal plants acquired from their ancestors, showing that the knowledge passed from generation to generation. Twenty-seven plant varieties were cited, and these are of great importance to the community in the prevention and combat of common diseases. The most cited plant was mint (Mentha $s p$ ) and malvarisco (Plectranthus ambroinicus) with used for gastrointestinal diseases, and respiratory diseases and the most used parts were the tea leaf. Therefore, the medicinal plants is a fundamental alternative in the combat of some diseases.
\end{abstract}

KEYWORDS: traditional knowledge, ethnoknowledge, phytotherapy.

\section{INTRODUÇÃO}

O relacionamento do ser humano com as plantas, numa perspectiva etnobotânica, é relatado desde a antiguidade até os tempos atuais, com inúmeras destinações e funções ambientais dos vegetais no cotidiano humano: alimentação, produção de remédios, combustível, aromatização, ornamentação, confecção de artesanatos, dentre outros (CASSAS et al., 2016). Assim, a etnobotânica busca resgatar e preservar os conhecimentos tradicionais das pessoas em relação às espécies, seus usos, manejos e relações com o ambiente e, através do saber local permite compreender o aproveitamento, obtendo informações sobre as espécies vegetais úteis e possibilitando o registro da estrutura de organização, composição, manejo e função das plantas (DAVID; PASA, 2015).

As plantas medicinais são utilizadas desde os primórdios das civilizações, sendo no passado usadas como o principal meio de tratamento que a população dispunha para a cura das enfermidades e, a partir desses conhecimentos populares foram descobertos, alguns medicamentos que são utilizados na medicina tradicional. Para Albuquerque et al. (2014), plantas medicinais são espécies vegetais com vários tipos de princípios ativos, que podem agir nos organismos humanos e animais, para combater muitas doenças, eliminando os agentes causadores como, vermes, fungos e bactérias, além de proporcionar uma forte ação preventiva nos problemas de saúde.

O uso de plantas medicinais por populações da área rural é oriundo dos conhecimentos acumulados mediante a relação direta dos seus membros com o meio ambiente e da propagação de uma série de informações tendo como influência 
o uso tradicional transmitido oralmente entre as diferentes gerações (MOREIRA et al., 2002). Diante disso é comum encontrar em comunidades rurais várias receitas de como tratar e curar diversas enfermidades por meio do uso de plantas, que são cultivadas em sua maioria, no entorno da casa ou no quintal. Havendo também o uso de plantas nativas encontradas na mata. Couto-Waltrich et al. (2017) afirmam que comunidades rurais têm naturalmente proximidade com a biodiversidade vegetal no local onde vivem.

Sales et al. (2015) destacam o Brasil como sendo a maior diversidade vegetal do planeta e ampla sociodiversidade, com enorme potencial no desenvolvimento da fitoterapia. Salientam ainda, que a utilização de plantas medicinais é um processo de produção e reprodução de diversos saberes e práticas, resultante de diferentes culturas, decorrente da organização social e produtiva de comunidades tradicionais. Segundo Rodrigues (2016), cerca de $20 \%$ da totalidade de espécies de plantas do mundo inteiro, apresenta algum tipo de propriedade terapêutica.

Foi pela experimentação e avaliação, por povos primitivos, que determinadas propriedades terapêuticas das plantas tiveram seus valores descobertos e difundidos, constituindo-se como elemento da cultura popular (PEREIRA et al., 2016). No entanto, o conhecimento botânico popular encontra-se ameaçado por fatores como, pressões econômicas e culturais externas a comunidade, desinteresse deste saber pelos mais jovens, êxodo rural, o que leva ao desuso do conhecimento popular e, consequentemente, o desaparecimento (MERHY; SANTOS, 2017).

Seria importante e necessário criar estratégias que aproximem esse conhecimento popular de instituições de pesquisa (MAIOLI-AZAVEDO; FONSECAKRUEL, 2007), a fim de possibilitar a aproximação por meio de investigações etnobotânicas, por serem reconhecidas pela comunidade científica como a principal estratégia para a seleção de plantas a terem suas atividades avaliadas (ALBUQUERQUE; HANAZAKI, 2006).

Dessa forma, o presente estudo objetivou avaliar o etnoconhecimento quanto ao saber quais as plantas medicinais, que partes da planta são utilizadas e como são usadas, no combate aos problemas de saúde dos moradores na Comunidade da Brenha em Redenção, no Ceará.

\section{MATERIAL E MÉTODOS Localização e caracterização da área de estudo}

O trabalho foi realizado na Comunidade da Brenha, localizada no município de Redenção-Ceará, que faz parte da região do Maciço de Baturité, no estado do Ceará. Está situada à latitude de 0413'33"Sul, longitude 3843'53" Oeste e altitude de $88,8 \mathrm{~m}$. Sobre os aspectos climáticos, o clima local é tropical quente úmido, com temperatura média anual entre $26{ }^{\circ} \mathrm{C}$ a $28{ }^{\circ} \mathrm{C}$. As chuvas ocorrem de janeiro a abril, com a precipitação pluviométrica média de $1.062 \mathrm{~mm}$ por ano.

A comunidade da Brenha fica a $18 \mathrm{Km}$ distante do município de Redenção, o qual possui uma área de $223,63 \mathrm{~km}^{2}$, com uma população de 27.358 habitantes. 0 município tem a economia baseada no plantio de bananas, principalmente nas serras que rodeiam, já que faz parte do Maciço de Baturité, bem como a plantação da cana-de-açúcar, milho e feijão. A pecuária é voltada pela criação de suínos, bovinos caprinos e avicultura. O relevo da área se caracteriza por maciços residuais e depressões sertanejas, o solo, planossolo solódico e podzólico vermelho-amarelo. a vegetação é formada pela caatinga arbustiva densa e floresta subcaducifólia tropical pluvial (IPECE, 2017). 


\section{Período de estudo}

O trabalho foi realizado de maio a dezembro de 2017 com 35 famílias residentes e nascidas na Comunidade da Brenha, as pessoas entrevistadas tinham idades entre 25 a 78 anos, pertencentes a ambos os sexos.

\section{Caracterização do Estudo}

Inicialmente, os objetivos da pesquisa foram bem explanados na Comunidade da Brenha, sendo solicitada a colaboração voluntária dos moradores, sendo que as pessoas a serem entrevistadas assinaram o termo de consentimento livre e esclarecido (TCLE). Uma vez aceita a participação, deu-se início à entrevista. A pesquisa do etnoconhecimento sobre as plantas medicinais foi analisada através das abordagens quantitativa e qualitativa.

\section{Coleta dos dados}

Para realizar o trabalho sobre o levantamento etnobotânico do uso de plantas medicinais foi utilizado como recurso metodológico um questionário estruturado quanti-qualitativo durante as entrevistas com os comunitários.

O questionário foi composto por 15 perguntas que abordavam o conhecimento tradicional sobre quais as espécies de plantas medicinais utilizadas pela comunidade, as indicações terapêuticas, os nomes populares, as formas de uso, a frequência de uso, as partes da planta utilizadas, o modo de preparo e suas aplicações, como também, a forma de cultivo das plantas. Também conhecer como são repassados os saberes entre as gerações. Cada planta mencionada foi fotografada e anotadas as informações relevantes para o reconhecimento das espécies.

\section{Análise estatística}

Os dados coletados foram organizados e analisados por meio de métodos da estatística descritiva, com sínteses apresentadas na forma de gráfico e quadro pelo Word e Excel. As frequências foram calculadas pela seguinte fórmula:

A frequência percentual (\%) foi calculada pela seguinte fórmula:

$$
F p_{i}(\%)=\left(\frac{f_{i}}{n}\right) \times 100
$$

onde, $\mathrm{Fp}_{\mathrm{i}}$ : frequência percentual, $\mathrm{f}_{\mathrm{i}}$ : frequência absoluta e $\mathrm{n}$ : número de plantas.

\section{RESULTADOS E DISCUSSÃO}

A comunidade da Brenha é composta por agricultores familiares tradicionais, que têm seu modo de vida indissociável do uso sustentável da biodiversidade e dos bens comuns, passando o conhecimento adquirido através dos tempos de pai para filho. Durante o trabalho foi observado que os moradores possuem um vasto conhecimento sobre o uso e manejo das plantas nos seus quintais, desenvolvendo técnicas de cultivo que garantem o equilíbrio ecológico. Para a manutenção das plantas medicinais utilizam os estercos bovino e caprino para fazer a adubação orgânica, que dentro da comunidade funciona como um escambo, isto é, as trocas de produtos entre os vizinhos, especificamente para manter a saúde e vitalidade dos cultivos. De acordo com Pilla et al. (2006) a predominância de ervas na medicina popular pode estar relacionada ao fato de serem cultivadas geralmente nos quintais, o que facilita a obtenção desses recursos vegetais.

AGRARIAN ACADEMY, Centro Científico Conhecer-Goiânia, v.5, n.9; p. 4122018 
Foram entrevistadas 35 famílias, respondendo ao questionário 31 mulheres e quatro homens, assim foi observado que as mulheres participam com mais frequência, o que também foi encontrado por Vásquez et al. (2014), que em trabalho sobre etnobotânica de plantas medicinais realizadas em comunidades ribeirinhas no Amazonas, relataram que dos 164 moradores entrevistados durante as pesquisas, 102 foram mulheres e 62 homens. Os autores observaram que a participação da mulher no cultivo de plantas medicinais é mais frequente, pois estas localizam-se em volta das residências.

Ademais, as mulheres da Comunidade da Brenha quando entrevistadas ficaram mais à vontade para falar sobre as plantas medicinais, também possuem a característica de recordarem com mais facilidade quais e para que servem, as plantas medicinais que são cultivadas em seus quintais. Essa característica também foi observada por Carvalho et al. (2013), Vásquez et al. (2014), Silva et al. (2015) e Cajaiba et al. (2016) em estudos etnobotânicos. Neste trabalho foi percebido que os quintais representam também, espaços de sociabilidade entre os vizinhos, para a troca de saberes e de material genético, através da doação de mudas e sementes, prática comum entre os pequenos agricultores familiares, especialmente as mulheres fazem parte deste hábito.

A comunidade da Brenha, por ser distante 18 quilômetros da zona urbana e possui difícil acesso ao setor de saúde pública, as plantas medicinais são e se tornam indispensáveis para os comunitários, sendo também, utilizadas pelos agricultores como terapia complementar nos tratamentos de algumas enfermidades. Sendo assim, as plantas medicinais são utilizadas como forma de atendimento primário para as necessidades básicas de saúde da comunidade, muitas vezes, aliviam sintomas e até a cura das doenças mais frequentes e comuns. Para Rosa e Orey (2014), quando os membros de um determinado grupo cultural e comunitário, possuem uma profunda relação com o meio natural onde estão inseridos com as plantas e animais, pode se concluir que desenvolveram um alto grau de conhecimento etnobiológico, que pode servir como base para a estruturação de modelos sustentáveis do coletivo, inclusive de saúde.

Este trabalho também demonstrou que na comunidade da Brenha o conhecimento sobre o uso das plantas medicinais é repassado pelas pessoas mais idosas de uma família como os avós, pais ou tios, bem como, por benzedeiras ou rezadeiras e curandeiros, que são responsáveis pelas formulações à base de plantas medicinais, para aliviar, prevenir e até curar as enfermidades locais. Também conhecem o uso das plantas tidas como protetoras, como é o caso da arruda (Ruta graveolenes $L$.), utilizada no saber popular, para espantar o "mau olhado". Oliveira et al. (2018) salientam que é notório todo o reconhecimento da população idosa a respeito dos conhecimentos adquiridos serem norteados através das gerações passadas, de tal modo que estes saberes são transmitidos a outras pessoas, consolidando a cultura familiar.

Cavalcante e Silva (2014), consideram que os estudos etnobotânicos são importantes, pois avaliam de que maneira os habitantes reúnem conhecimentos e como são transmitidos para as novas gerações. Moreira et al. (2002) afirmam que a transmissão do conhecimento popular, aliado aos trabalhos sobre o uso terapêutico dos vegetais, é um reforço contra a ameaça de extinção de várias espécies, sendo muitas ainda desconhecidas pela ciência. Strachulski e Floriani (2013) acrescentam que pesquisas de cunho etnobotânico têm apontado grande série de classificações e taxonomias nativas sobre elementos vegetais locais.

AGRARIAN ACADEMY, Centro Científico Conhecer - Goiânia, v.5, n.9; p. 4132018 
$\mathrm{Na}$ comunidade da Brenha, a partir das entrevistas realizadas foi elaborada uma lista com 27 espécies de plantas medicinais (Figura 1). Foram citadas 15 famílias (QUADRO 1) e as plantas medicinais mais citadas foram: hortelã (Mentha sp.): 7,9\%; malvarisco (Plectranthus ambroinicus): 6,5\%; capim santo (Cymbopogon citratus): 5,9\%; corama (Bryophyllum pinnatum): $5,6 \%$; boldo (Plectrantus barbatus): 5,1\%; laranjeira (Citrus sinensis): 5,1\%; limão (Citrus limonum): 4,2\%; erva cidreira (Melissa officinalis): 4,2\%; mastruz (Dysphania ambrosioides): 4,2\%; ameixa da caatinga (Ximenia americana): 3,7\% e manjericão (Ocimum basilicum): 3,4\%.

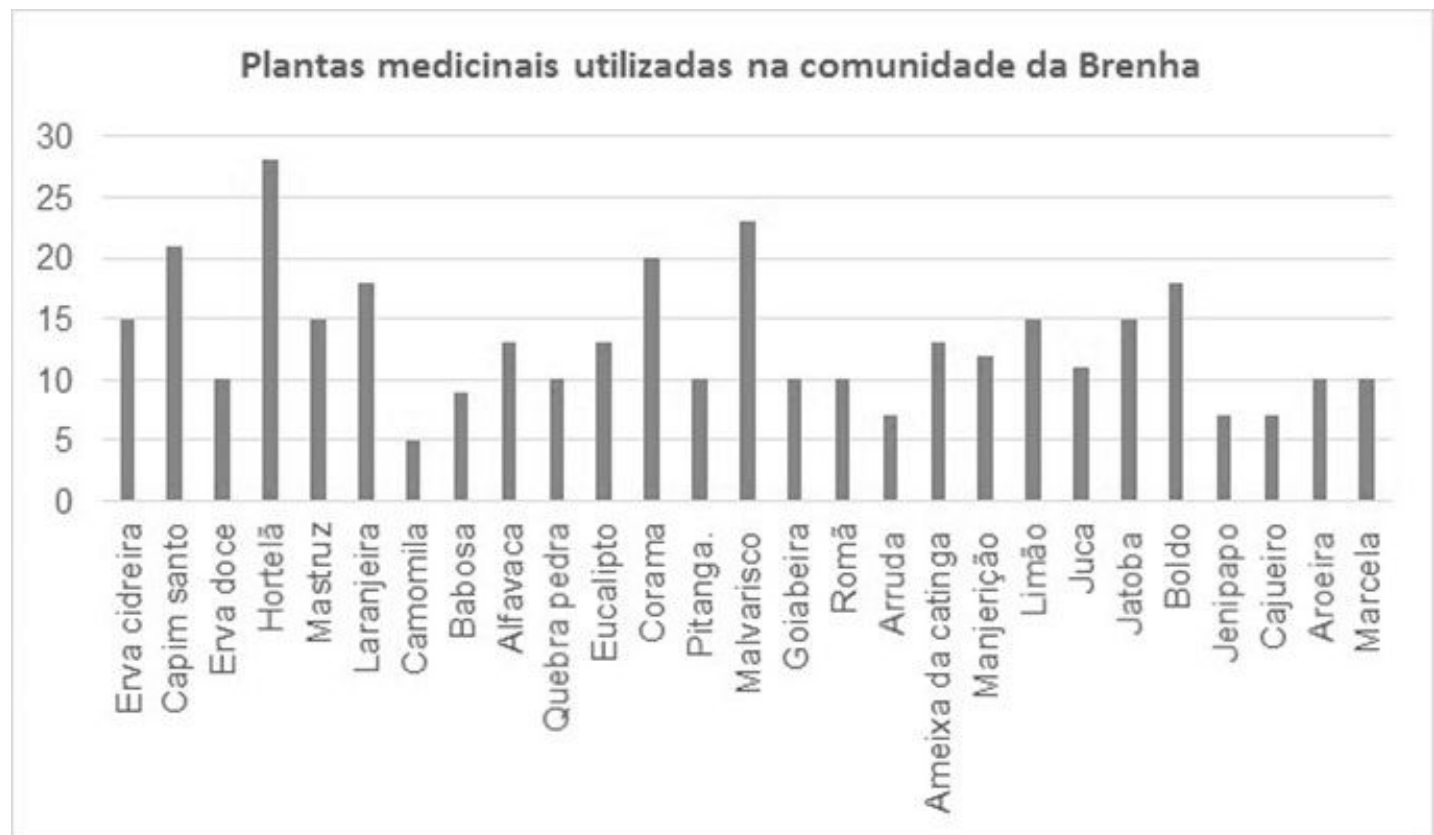

FIGURA 1 Espécies de plantas medicinais utilizadas pela Comunidade da Brenha, Redenção-CE.

Das 27 plantas com atividades medicinais citadas na comunidade da Brenha (QUADRO 1), muitas aparecem em outros trabalhos etnobotânicos, como o boldo, hortelã, quebra-pedra, camomila, capim-santo entre outras (PEREIRA et al., 2005; ALBUQUERQUE; HANAZAKI, 2006; PILLA et al., 2006). Salienta-se que espécies como o boldo e a hortelã, não são nativas do Brasil, são oriundas da África e Europa respectivamente (PILLA et al., 2006). Ângelo e Ribeiro (2014) verificaram que no município baiano de Cordeiros as plantas medicinais mais mencionadas pelos idosos entrevistados foram: capim santo 72 vezes, erva doce 47 , erva cidreira 43 e hortelã 31.

Durante as entrevistas foi observado que as partes das plantas utilizadas foram: folhas $(55,17 \%)$, cascas $(24,13 \%)$, semente $(6,89 \%)$, fruto $(6,89 \%)$, raiz $(3,47 \%)$ e flor $(3,45 \%)$. Merhy e Santos (2017) encontraram as folhas como o órgão das plantas medicinais mais utilizado no preparo dos remédios caseiros em 70,3\% dos entrevistados, semelhantes aos achados de diversos autores (PEREIRA et al., 2005; PINTO et al., 2006; LIPORACCI; SIMÃO, 2013; ARAÚJO; LEMOS, 2015; DAVID; PASA, 2015; OLIVEIRA et al., 2018).

A predominância das folhas serem usadas nos medicamentos caseiros deve ser atribuída a maior facilidade de coleta e a disponibilidade durante 0 ano (PEREIRA et al., 2005), além do que, segundo Santos et al. (2008), a maioria dos compostos ativos é encontrada nas folhas e a coleta não causa muitos danos a AGRARIAN ACADEMY, Centro Científico Conhecer - Goiânia, v.5, n.9; p. 4142018 
planta, permitindo a preservação e uso continuado. O uso da flor como a parte da planta medicinal utilizada teve valor semelhante ao deste estudo, no levantamento de Liporacci e Simão (2013) com 3,4\%.

Neste estudo, o uso da casca $(24,13 \%)$ pelos comunitários da Brenha foi bem superior aos achados de Merhy e Santos (2017) que encontraram apenas 2,1\%. Diferentemente dos valores encontrados por Coutinho et al. (2002), em que a casca foi a parte da planta mais citada, em estudo no Maranhão.

QUADRO 1. Plantas medicinais citadas pelos entrevistados da Comunidade da Brenha, no município de Redenção, Ceará.

\begin{tabular}{|c|c|c|c|}
\hline FAMÍLIA & NOME CIENTÍFICO & $\begin{array}{c}\text { NOME } \\
\text { POPULAR }\end{array}$ & $\begin{array}{c}\text { № } \\
\text { CITACOES }\end{array}$ \\
\hline \multirow[t]{2}{*}{ Anacardiaceae } & Anacardium occidentale & Cajueiro & 7 \\
\hline & Myracrodruon urundeuva & Aroeira & 10 \\
\hline Asphodelaceae & Aloe Vera & Babosa & 9 \\
\hline Apiaceae & Pimpinella anisum & Erva doce & 10 \\
\hline \multirow{2}{*}{ Asteraceae } & Matricaria chamomilla & Camomila & 5 \\
\hline & Achyrocline satureioides & Marcela & 10 \\
\hline Chenopodiaceae & Dysphania ambrosioides & Mastruz & 15 \\
\hline Crassulaceae & Bryophyllum pinnatum & Corama & 20 \\
\hline Euphorbiaceae & Phillathus niruri Roxb & Quebra pedra & 10 \\
\hline \multirow[t]{2}{*}{ Fabaceae } & Caesalpinia férrea & Jucá & 11 \\
\hline & Hymenaea courbaril & Jatobá & 15 \\
\hline \multirow[t]{6}{*}{ Lamiceae } & Mentha sp & Hortelã & 28 \\
\hline & Melissa officinales & Erva cidreira & 15 \\
\hline & Peumus boldus & Boldo & 18 \\
\hline & Plectrantrhus ambroinicus & Malvarisco & 23 \\
\hline & Ocimum gratissimum & Alfavaca & 13 \\
\hline & Ocimum basilicum & Manjericão & 12 \\
\hline \multirow[t]{3}{*}{ Myrtaceae } & Eugenia uniflora & Pitanga & 10 \\
\hline & Eucalyptus & Eucalipto & 13 \\
\hline & Psidium guajava & Goiabeira & 10 \\
\hline Olacaceae & Ximenia americana $L$ & $\begin{array}{l}\text { Ameixa } \\
\text { da caatinga }\end{array}$ & 13 \\
\hline Poaceae & Cymbopogon citratus & Capim santo & 21 \\
\hline Punicaceae & Punica granatum $\mathrm{L}$ & Romã & 10 \\
\hline Rubiáceas & Genipa americana & Jenipapo & 7 \\
\hline \multirow[t]{3}{*}{ Rutaceae } & Citrus sinensis & Laranjeira & 18 \\
\hline & Citrus limonum & Limão & 15 \\
\hline & Ruta graveolenes & Arruda & 7 \\
\hline
\end{tabular}


Com relação a forma de uso das plantas medicinais nos processos de curas das doenças este estudo na comunidade da Brenha encontrou os usos (QUADRO 2 2) na forma de: chá $(63 \%)$, lambedor $(29,6 \%)$, suco $(7,4 \%)$, banho $(11,1 \%)$, uso tópico $(3,7 \%)$ e gargarejo (3,7\%). Pasa et al. (2005), Liporacci e Simão (2013) e Bezerra et al. (2016), também encontraram o chá como a forma de preparo mais utilizada e expressiva, valores semelhantes ao deste estudo foram encontrados por Merhy e Santos (2017) com 61,5\% do modo de preparo pelo chá. No entanto, o uso de plantas medicinais na forma de banhos que neste estudo foi de $11,1 \%$ não corresponde ao encontrado em 1,1\% nas entrevistas de Pasa et al. (2005) e Merhy e Santos (2017) sobre a forma de usar as plantas nas curas.

QUADRO 2. Indicações para os agravos que ocorrem na comunidade da Brenha.

\begin{tabular}{|c|c|c|c|c|c|}
\hline FAMÍLIA & $\begin{array}{c}\text { NOME } \\
\text { CIENTIFICO }\end{array}$ & $\begin{array}{c}\text { NOME } \\
\text { POPULAR }\end{array}$ & $\begin{array}{l}\text { PARTES } \\
\text { USADAS }\end{array}$ & $\begin{array}{l}\text { MODO } \\
\text { DE USAR }\end{array}$ & INDICAÇÕES \\
\hline Anacardiaceae & $\begin{array}{l}\text { Anacardium } \\
\text { occidentale }\end{array}$ & Cajueiro & Casca & Lambedor & Gripe \\
\hline Asphodelaceae & Aloe vera & Babosa & Folha & $\begin{array}{l}\text { Lambedor } \\
\text { uso tópico }\end{array}$ & $\begin{array}{l}\text { Inflamações } \\
\text { Cicatrizante }\end{array}$ \\
\hline Apiaceae & Pimpinella anisum & Erva doce & Semente & Chá & Calmante \\
\hline \multirow[t]{2}{*}{ Asteraceae } & $\begin{array}{l}\text { Matricaria } \\
\text { chamomilla }\end{array}$ & Camomila & Folha/ flor & Chá & $\begin{array}{l}\text { Gripes } \\
\text { resfriados }\end{array}$ \\
\hline & $\begin{array}{l}\text { Achyrocline } \\
\text { satureioides }\end{array}$ & Marcela & $\begin{array}{l}\text { Folha, } \\
\text { semente }\end{array}$ & Chá & Má digestão \\
\hline Chenopodiaceae & $\begin{array}{l}\text { Dysphania } \\
\text { ambrosoides }\end{array}$ & Mastruz & Folha & Suco & Gripe \\
\hline Crassulaceae & $\begin{array}{l}\text { Bryophyllum } \\
\text { pinnatum }\end{array}$ & Corama & Folha & Lambedor & Inflamações \\
\hline Euphorbiaceae & Phillathus niruri & Quebra pedra & Raiz & Chá & Cálculo renal \\
\hline \multirow{2}{*}{ Fabaceae } & Caesalpinia férrea & Jucá & Casca & Lambedor & Gripe \\
\hline & Hymenaea courbaril & Jatobá & Casca & Lambedor & Gripe \\
\hline \multirow[t]{6}{*}{ Lamiceae } & Mentha sp & Hortelã & Folha & Chá & Má digestão \\
\hline & Melissa officinalis & Erva cidreira & Folha & Chá & Calmante \\
\hline & Peumus boldus & Boldo & Folha & Chá & Má digestão \\
\hline & $\begin{array}{l}\text { Ocimum } \\
\text { gratissimum }\end{array}$ & Alfavaca & Folha & $\begin{array}{l}\text { Chá } \\
\text { inalação }\end{array}$ & $\begin{array}{l}\text { Gripe } \\
\text { resfriado }\end{array}$ \\
\hline & Ocimum basilicum & Manjericão & Folha & $\begin{array}{l}\text { Chá } \\
\text { banho }\end{array}$ & Gripe \\
\hline & $\begin{array}{l}\text { Plectranthus } \\
\text { ambroinnicus }\end{array}$ & Malvarisco & Folha & $\begin{array}{l}\text { Chá } \\
\text { lambedor }\end{array}$ & Gripe \\
\hline \multirow[t]{3}{*}{ Myrtaceae } & Eugenia uniflora & Pitanga & Folha & Chá & Gastrite \\
\hline & Psidium guajava & Goiabeira & Folha & Chá & Diarreia \\
\hline & & & Casca & Lambedor & Gripe \\
\hline Olacaceae & Ximenia americana & $\begin{array}{l}\text { Ameixa } \\
\text { da caatinga }\end{array}$ & Casca & Lambedor & Gripe \\
\hline Poaceae & $\begin{array}{l}\text { Cymbopogon } \\
\text { citratus }\end{array}$ & Capim santo & Folha & Chá & Calmante \\
\hline Punicaceae & Punica granatum & Romã & Casca & $\begin{array}{l}\text { Lambedor } \\
\text { gargarejo }\end{array}$ & $\begin{array}{l}\text { Gripe } \\
\text { Garganta }\end{array}$ \\
\hline Rubiáceas & Genipa americana & Jenipapo & Fruto & Suco & Anemia \\
\hline \multirow[t]{3}{*}{ Rutaceae } & Citrus sinensis & Laranjeira & $\begin{array}{l}\text { Casca } \\
\text { folha }\end{array}$ & Chá & $\begin{array}{l}\text { Calmante } \\
\text { Gastrite }\end{array}$ \\
\hline & Citrus $x$ limon & Limão & Fruto & Suco & Gripe \\
\hline & Ruta graveolenes & Arruda & Folha & Chá & $\begin{array}{l}\text { Cólica } \\
\text { mau olhado }\end{array}$ \\
\hline
\end{tabular}


As plantas medicinais podem ser utilizadas sob a forma de infusão, decocção, maceração, tintura, extratos fluido, mole ou seco, pomadas, cremes, xaropes, inalação, cataplasma, compressa, gargarejo ou bochecho (FERNANDES; KRUPEK 2014).

Assim, é notório que grande parte dos vegetais utilizados como remédios pelas populações locais está relacionado com o tratamento de enfermidades mais simples, que fazem parte da atenção primária em saúde, como por exemplo: gripes, resfriados, febre, gastrite, úlcera, problemas do fígado e estômago, dores de cabeça e feridas. As entrevistas na Comunidade da Brenha em Redenção (CE) revelaram as plantas citadas (QUADRO 2), com seus usos e aplicações nos problemas de saúde mais comuns dos comunitários.

Neste estudo, a planta medicinal mais citada na comunidade da Brenha foi a hortelã (Mentha $s p$ ) utilizando a folha na forma de chá para problemas digestivos. Liporacci e Simão (2013) também encontraram a hortelã como a mais citada em levantamento realizado em bairro mineiro do município de Ituiutaba, no entanto $50 \%$ dos usuários a indicavam para doenças do sistema respiratório, salientando a importância do etnoconhecimento local e regional sobre o uso das plantas medicinais.

\section{CONCLUSÃO}

Os moradores da comunidade da Brenha possuem conhecimento sobre as plantas medicinais, em termos de reconhecimento, formas de preparo, consumo motivado e presença nos quintais das famílias. Sendo que, esta cultura popular ainda prevalece na comunidade, por se tratar de uma alternativa de baixo custo e eficaz, além de ser uma herança passada de geração a geração ao longo do tempo.

A transmissão e a preservação de conhecimentos tradicionais familiares são imprescindíveis para a manutenção da identidade cultural das comunidades rurais, por isso, as pesquisas que corroborem com a conservação do etnoconhecimento são fundamentais.

\section{REFERÊNCIAS}

ALBUQUERQUE, U.P.; HANAZAKI, N. As pesquisas etnodirigidas na descoberta de novos fármacos de interesse médico e farmacêutico: fragilidades e pespectivas. Revista Brasileira de Farmacognosia, v.16, n. supl, p.678-689, 2006. Disponível em: $\quad<h t t p: / / w w w . s c i e l o . b r / p d f / r b f a r / v 16 s 0 / a 15 v 16 s 0 . p d f>, \quad$ DOI: http://dx.doi.org/10.1590/S0102-695X2006000500015.

ALBUQUERQUE, U.P.; MEDEIROS, P.M.; RAMOS, M.A.; JÚNIOR, W.S.F.; NASCIMENTO, A.L.B.; AVILEZ, W.M.T.; MELO, J.G. Are ethnopharmacological surveys useful for the Discovery and development of drugs from medicinal plants? Revista Brasileira de Farmacognosia-Brazilian Journal of Pharmacognosy, v. 24, p.110-115, 2014. Disponível em: <http://www.scielo.br/pdf/rbfar/v24n2/0102695X-rbfar-24-02-00110.pdf>, DOI: http://dx.doi.org/10.1016/j.bjp.2014.04.003

ÂNGELO, T.; RIBEIRO, C.C. Utilização de plantas medicinais e medicamentos fitoterápicos por idosos. Revista Eletrônica da Fainor, v.7, n.1, p.18-31, 2014. Disponível em: <http://srv02.fainor.com.br/revista/index.php/memorias/article/viewFile/246/188>. 
ARAÚJO, J.L; LEMOS, J.R. Estudo etnobotânico sobre plantas medicinais na comunidade de Curral Velho, Luís Correia, Piauí, Brasil. Revista Biotemas, v.28, n.2, p. 125-136, junho de 2015. Disponível em: <https://revistas.ufpr.br/academica/article/view/493/406>, DOI: 10.5007/21757925.2015v28n2p125.

BEZERRA, D.S.; LIMA, A.K.B.S.; BONZI, A.R.B.; FERREIRA, R.S.; BONA NETO, E.; PINTO, D.S. Fitoterapia e uso de plantas medicinais: adjuvantes no controle da pressão arterial. Temas em Saúde, v.16, n.4, p.262-276, 2016. ISSN: 2447-2131. Disponível em: http://temasemsaude.com/wp-content/uploads/2017/01/16417.pdf.

CAJAIBA, R.L.; SILVA, W.B.; SOUSA, R.D.N.; SOUSA, A.S. Levantamento etnobotânico de plantas medicinais comercializadas no município de Uruará, Pará, Brasil. Revista Biotemas, v.29, n.1, p.115-131. 2016. Disponível em: $<$ https://periodicos.ufsc.br/index.php/biotemas/article/view/2175-

7925.2016v29n1p115/31236>, $\quad$ DOI: $\quad$ https://doi.org/10.5007/2175 7925.2016v29n1p115.

CARVALHO, J.S.B.; MARTINS, J.D.L.; MENDONÇA, M.C.S.; LIMA, L.D. Uso popular das plantas medicinais na comunidade da Várzea, Garanhuns-PE. Revista de Biologia e Ciências da Terra, v.13, n.2, p.58-65, 2013. Disponível em: <http://joaootavio.com.br/bioterra/workspace/uploads/artigos/768-2912-1-pb53df96b4789a6.pdf>.

CASSAS, F.; SILVA, D.S., BARROS, C.; REIS, N.F.C.; RODRIGUES, E. Canteiros de plantas medicinais, condimentares e tóxicas como ferramenta de promoção à saúde no jardim botânico de Diadema, SP, Brasil. Revista Ciência Ext. v.12, n.2, p.37-46, 2016. Disponível em: <http://ojs.unesp.br/index.php/revista_proex/article/view/1337/1229>.

CAVALCANTE, A.C.P.; SILVA, A.G. Levantamento etnobotânica e utilização de plantas medicinais na comunidade Moura, Bananeiras-PB. Revista Monografias Ambientais-REMOA, v.14, n.2, p.3225-3230, 2014. Disponível em: <https://periodicos.ufsm.br/remoa/article/view/12749/pdf>, http://dx.doi.org/10.5902/2236130812749

COUTINHO, D.F.; TRAVASSOS, L.M.A.; AMARAL, F.M.M. Estudo etnobotânico de plantas medicinais utilizadas em comunidades indígenas no estado do Maranhão Brasil. Visão Acadêmica, v.3, n.1, p.7-12, 2002. Disponível em: <https://revistas.ufpr.br/academica/article/view/493/406>, http://dx.doi.org/10.5380/acd.v3i1.493

COUTO-WALTRICH, C.; BOFF. P.; BOFF, M.I.C. Etnoconhecimento associado às amoreiras-brancas (Rubus spp.) ocorrentes na floresta ombrófila mista, Santa Catarina, Brasil. Revista de la Faculdade de Agronomia, La Plata, v.116, n.1, p.1318, 2017.

DAVID, M.; PASA, M.C. As plantas medicinais e a etnobotânica em Várzea Grande, AGRARIAN ACADEMY, Centro Científico Conhecer - Goiânia, v.5, n.9; p. 4182018 
MT, Brasil. Interações, Campo Grande, v.16, n.1, p.97-108, jan./jun. 2015. Disponível em: <http://dx.doi.org/10.1590/1518-70122015108> DOl: 10.1590/151870122015108

FERNANDES, N.K.; KRUPEK, R.A. O uso de plantas medicinais por grupos da terceira idade no município de União da Vitória (PR). Arquivos do MUDI, v.18, n.3, p. 49-64, 2014. Disponível em: <www.periodicos.uem.br/ojs/index.php/ArqMudi/article/download/26905/pdf_81>.

IPECE - Instituto de Pesquisa e Estratégia econômica do Ceará, Perfil municipal de Redenção, $2017 . \quad$ Disponível em: <http://www.ipece.ce.gov.br/perfil_basico_municipal/2017/Redencao.pdf>.

LIPORACCI, H.S.N.; SIMÃO, D.G. Levantamento etnobotânico de plantas medicinais nos quintais do Bairro Novo Horizonte, Ituiutaba, MG. Revista Brasileira de Plantas Medicinais, v.15, n.4, p.529-540, 2013. Disponível em: <http://www.scielo.br/pdf/rbpm/v15n4/a09v15n4.pdf>. DOI: http://dx.doi.org/10.1590/S1516-05722013000400009.

MAIOLI-AZEVEDO, V.; FONSECA-KRUEL, V.S. Plantas medicinais e ritualísticas vendidas em feiras livres no Município do Rio de Janeiro, RJ, Brasil: estudo de caso nas zonas Norte e Sul. Acta Botânica Brasilica, v.21, n.2, p.263-275, 2007. Disponível em: <http://www.scielo.br/pdf/abb/v21n2/02.pdf>, $\quad$ DOI: http://dx.doi.org/10.1590/S0102-33062007000200002.

MERHY, T.S.M.; SANTOS, M.G. A etnobotânica na escola: interagindo saberes no ensino fundamental. Revista Práxis, v.9, n.17, p.9-22, 2017. Disponível em: $<$ http://revistas.unifoa.edu.br/index.php/praxis/article/view/676/1165>.

MOREIRA, R.C.T.; COSTA, L.C.B.; COSTA, R.C.S.; ROCHA, E.A. Abordagem etnobotânica acerca do uso de plantas medicinais na Vila Cachoeira, Ilhéus, Bahia, Brasil. Acta Farmacéutica Bonaerense, v. 21, n. 3, p. 205-211, 2002. Disponível em:

<http://www.latamjpharm.org/trabajos/21/3/LAJOP_21_3_3_1_L8H8YN8M78.pdf>.

OLIVEIRA, T.L.; NERI, G.F.; OLIVEIRA, V.J.S.; BRITO, N.M. Utilização de plantas medicinais por idosos em três bairros do município de Conceição do Almeida - BA. Journal of Biology \& Pharmacy and Agricultural Management, v. 14, n. 2, p. 138151, abr/jun $2018 . \quad$ Disponível em: <http://revista.uepb.edu.br/index.php/biofarm/article/view/3947>.

PASA, M.C.; SOARES, J.J.; GUARIM NETO, G. Estudo etnobotânico na comunidade de Conceição-Açu (alto da bacia do rio Aricá Açu, MT, Brasil). Acta Botanica Brasilica, Belo Horizonte, v. 19, n. 2, p. 195-207, 2005. Disponível em: <http://www.scielo.br/pdf/abb/v19n2/26213.pdf>. http://dx.doi.org/10.1590/S0102-33062005000200001

PEREIRA, C.O.; LIMA, E.O.; OLIVEIRA, R. A.G.; TOLEDO, M.S.; AZEVEDO, A.K.A.; GUERRA, M.F.; PEREIRA, R.C. Abordagem etnobotânica de plantas medicinais AGRARIAN ACADEMY, Centro Científico Conhecer - Goiânia, v.5, n.9; p. 4192018 
utilizadas em dermatologia na cidade de João Pessoa-Paraíba, Brasil. Revista Brasileira de Plantas Medicinais, v.7, n.3, p.9-17, 2005. Disponível em: <http://www.sbpmed.org.br/download/issn_05_3/artigo2_v7_n3.pdf>.

PEREIRA, A.R.A.; VELHO, A.P.M.; CORTEZ, D.A.G.; SZERWIESKI, L.L.D.; CORTEZ, L.E.R. Uso tradicional de plantas medicinais por idosos. Revista Rene, v. 17, n.3, p.427-434, 2016. Disponível em: <http://periodicos.ufc.br/rene/article/view/3487/pdf>, http://dx.doi.org/10.15253/rev\%20rene.v17i3.3487

PILLA, M.A.C.; AMOROZO, M.C.M.; FURLAN, A. Obtenção e uso de plantas medicinais no distrito de Martim Francisco, município de Mogi Mirim, SP, Brasil, Acta Botanica Brasilica, v.20, n.4, p.789-802, 2006. Disponível em: <http://www.scielo.br/pdf/abb/v20n4/05.pdf>, DOI: http://dx.doi.org/10.1590/S010233062006000400005.

PINTO, E.P.P.; AMOROZO, M.C.M.; FURLAN A. Conhecimento popular sobre plantas medicinais em comunidades rurais de mata Atlântica - Itacaré, BA, Brasil. Acta Botanica. Brasilica, v.20, n.4, p.751-762, 2006. Disponível em: <http://www.scielo.br/pdf/abb/v20n4/01.pdf>, DOI: http://dx.doi.org/10.1590/S010233062006000400001

RODRIGUES, W. Competitividade e mudança institucional na cadeia produtiva de plantas medicinais no Brasil. Interações, v. 17, n. 2, p. 267-277, 2016. Disponível em: <http://www.scielo.br/pdf/inter/v17n2/1518-7012-inter-17-02-0267.pdf>, DOI: http://dx.doi.org/10.20435/1984042X2016210.

ROSA, M.; OREY, D.C. Interlocuções Polissêmicas entre a Etnomatemática e os Distintos Campos de Conhecimento Etno-x, Educação em Revista, Belo Horizonte v.30, n.03, p.63-97, 2014. Disponível em: <http://www.scielo.br/pdf/edur/v30n3/v30n3a04.pdf>, $\quad$ DOI: http://dx.doi.org/10.1590/S0102-46982014000300004.

SALES, M.D.C.; SARTOR, E.B.; GENTILLI, R.M.L. Etnobotânica e Etnofarmacologia: medicina tradicional e bioprospecção de fitoterápicos. Revista Salus, v.1, n. 1, p. 17-26, 2015. Disponível em: <http://www.salusjournal.org/wpcontent/plugins/download-attachments/includes/download.php?id=691>. $\quad$ DOI: https://dx.doi.org/10.5935/2447-7826.20150003

SANTOS, J.F.L.; AMOROZO, M.C.M.; MING, L.C. Uso popular de plantas medicinais na comunidade rural da Vargem Grande, Município de Natividade da Serra, SP. Revista Brasileira de Plantas Medicinais, v.10, n.3, p.67-81, 2008. Disponível em: <http://www.sbpmed.org.br/download/issn_08_3/artigo12_v10n3.pdf> .

SILVA, M.D.P.; MARINI, F.S.; MELO, R.S. Levantamento de plantas medicinais cultivadas no município de Solânea, agreste paraibano: reconhecimento e valorização do saber tradicional. Revista Brasileira de Plantas Medicinais, v.17, n.4, supl. II, p.881-890, 2015. Disponível em: <http://www.scielo.br/pdf/rbpm/v17n4s2/1516-0572-rbpm-17-4-s2-0881.pdf> 
http://dx.doi.org/10.1590/1983-084X/14_112.

STRACHULSKI, J.; FLORIANI, N. Conhecimento popular sobre plantas: um estudo etnobotânico na comunidade rural de Linha Criciumal, em Cândido de Abreu-PR. Revista Geografar, v.8, n.1, p.125-153, $2013 . \quad$ DOI: http://dx.doi.org/10.5380/geografar.v8i1.30327

VÁSQUEZ, S.P.F.; MENDONÇA, M.S.; NODA, S.N. Etnobotânica de plantas medicinais em comunidades ribeirinhas do Município de Manacapuru, Amazonas, Brasil. Acta Amazônica, v. 44, n. 4, p. 457-472, $2014 . \quad$ DOI: http://dx.doi.org/10.1590/1809-439220140042 